\title{
Dry Socket Following Teeth Extraction: Effect of Excessive Socket Saline Irrigation
}

\author{
AlHindi $\mathrm{M}^{*}$ \\ Department of Oral and Maxillofacial Surgery, College of Dentistry, King Saud University, Kingdom of Saudi Arabia
}

*Corresponding author: AlHindi M, Assistant Professor, Department of Oral and Maxillofacial Surgery, College of Dentistry, King Saud University, Kingdom of Saudi Arabia, Tel: +966568339994, E-mail: Mnoo2001@gmail. com

Citation: AlHindi M (2017) Dry Socket Following Teeth Extraction: Effect of Excessive Socket Saline Irrigation. J Oral Health Dent Sci 1: 105

Article history: Received: 29 August 2017, Accepted: 17 October 2017, Published: 19 October 2017

\begin{abstract}
Introduction: Alveolar osteitis, "dry socket", is reported among the most common complications following teeth extraction. Many controversies are present in the literature of the pathogenesis of alveolar osteitis, yet the exact mechanisms are not yet confirmed. Many factors in relation to alveolar osteitis were reported since 1963 including difficulty of surgery, lack of operator experience, location of the extracted tooth, patient's age, gender, smoking habits, oral contraceptives, bacterial infection, excessive irrigation with saline, single extraction versus multiple extractions, the presence of systemic disease, and local anesthetic with vasoconstrictor. No clear data are available in the literature to show the incidence of dry socket due to excessive socket Irrigation with saline.
\end{abstract}

Material and Methods: A total of 574 of teeth were extracted from patients attending the clinic of oral and maxillofacial surgery for different reasons between 31 December 2012 and 30 April 2013. Patients who have unilateral tooth extraction, received chemo or radiotherapy, syndromic patients and pregnant women were excluded from the study. Age, gender, Medical history, location of tooth, difficulty of extraction and the presence of smoking habit were reported. The patients were divided into two groups, in the first group (286 extractions) the extracted socket was irrigated with $20 \mathrm{cc}$ saline (done by the operator) and the second group (288 extractions) received no saline irrigation. All patients were followed up after extraction by one week and instructed to visit the clinic when they develop any signs or symptoms of discomfort related to the extraction site. Patients who developed alveolar osteitis were diagnosed according to the conventional sign and symptoms of dry socket and managed in the standard way.

Result: The total number of dry socket reported in this current study was 7 (1.2\%) cases, 6 of the cases were females. All these cases were related to extractions in the mandible. Of All cases received excessive socket saline irrigation, only 2 cases developed dry socket.

Conclusion: Excessive socket saline irrigation with syrinage after teeth extraction is not related to the development of dry socket as mentioned in the literature, other factors could share in that, but no clear reason could be related.

Keywords: Dry socket; Saline irrigation; Extraction

\section{Introduction}

Extraction is a common procedure that encountered during routine dental practice. Complications following extraction vary as intraoperative, immediate and late [1]. Alveolar osteitis, "dry socket", was reported among the most common complications following teeth extraction. It requires more visits to the surgeon and increases the cost of treatment in $45 \%$ of the patient [2,3]. Many terminologies for alveolar osteitis have been introduced in the literature due to controversy in understanding the cause of it. "Dry socket" was first described in 1896 by Crawford [4]. Following that many terminologies followed as "alveolar osteitis", "alveolitis", "localized osteitis", "alveolitis sicca dolorosa", "localized alveolar osteitis", "fibrinolytic alveolitis", "septic socket", "necrotic socket", and "alveolalgia" [5-7].

Alveolar osteitis is an acute inflammation of the alveolar bone around the extraction site which is characterized by severe pain. It usually starts between the first and the third day after extraction accompanied by a partial or total disintegrated blood clot within the alveolar socket with or without halitosis [6].

Many signs and symptoms of alveolar osteitis were reported in the literature including severe pain, presence of bear bone with 
empty socket, radiating pain towards the ear and temporal region, inflamed red gingival margin, possible low grade fever, halitosis, ipsilateral regional lymphadenopathy and possible grayish discharge [8-13,15].

The incidence of alveolar osteitis was reported in the literature between 0.5 to $5.6 \%$ and up to $30 \%$ in case of surgical extractions. In the study of MacGregor 1968, Field 1985 0.5\% - 5\% alveolar osteitis incidence was documented in routine teeth extractions $[16,17]$. While it was $1 \%$ to $37.5 \%$ after extraction of mandibular third molars in some other studies [10,18]. Blum 2002 reported the incidence of alveolar osteitis as 10 times more in surgical extraction than non-surgical. In the study of Younis and Abu Hantash 2011 the overall incidence of dry socket was 3.2\% (40 dry sockets in 1305 extractions) $[6,19]$.

Several factors have been reported in the literature regarding the pathogenesis of alveolar osteitis, yet the exact mechanisms are not yet confirmed.

Birn in his series of publications between 1963 and 1977 provided a better understanding of the pathogenesis of alveolar osteitis $[8,20,21]$. He suggested that the etiology of alveolar osteitis is due to an increased in local fibrinolysis leading to the disintegration of the clot. He explained that the fibrinolysis activity is the result of plasminogen pathway activation, which can be accomplished via direct (physiologic) or indirect (nonphysiologic) activator substances [8]. He justified that that direct activators are released after trauma to the alveolar bone cells caused by extraction while indirect activators are elaborated by bacteria present in the oral cavity [8].

Many factors in relation to alveolar osteitis were reported since 1963 [22]. In a thorough review conducted by Kolokythas and coworkers 2010 many risk factors were mentioned such as difficulty of Surgery, lack of Operator Experience, location of the extracted tooth as mandibular third molars, systemic disease, Oral Contraceptives, patient's Gender, smoking, physical dislodgement of the Clot, bacterial Infection, excessive Irrigation or curettage of alveolus, age of the Patient, single extraction versus multiple extractions and local anesthetic with vasoconstrictor [23]. The relation of dry socket and excessive saline irrigation after teeth extraction is not clear in the literature [24,25].

The aim of this study was to explore the effect of through socket saline irrigation after teeth extraction on the development of dry socket.

Hypothesis: There is no significant difference between the extracted socket irrigated thoroughly with saline by the operator and the one who didn't receive irrigation in the development of dry socket.

Nile Hypothesis: There is a significant difference between the extracted socket irrigated thoroughly with saline by the operator and the one who didn't receive irrigation in the development of dry socket.

\section{Materials and Methods}

A total of 574 teeth were extracted in the clinic of oral and maxillofacial surgery for different reasons in the period between the $31^{\text {st }}$ December 2013 and the $30^{\text {th }}$ April 2014.

Inclusion criteria included a healthy and medically compromised patient with bilateral extraction, while exclusion criteria included, unilateral tooth extraction, patients receiving chemo or radiotherapy, syndromic patients, and pregnant patients.

The age, gender, Medical history, number of teeth, the difficulty of extraction and the presence of smoking habit were reported.

The patients were divided into two groups; one group received a through socket irrigation of the extracted socket with 20 cc of saline in a disposable syringe which was completed by the maxillofacial surgeon who extracted the teeth (286 extractions). The other group (288 cases) received no irrigation after extraction. All patients had bilateral extraction, where they received through socket irrigation with a $20 \mathrm{cc}$ of saline in a disposable syringe immediately after extraction in one side while the other side received none.

All patients were consented before treatment where a brief discussion done and a choice given to them to participate in the study. Any patient who didn't agree to precipitate in the study was treated as planned.

Patients were given a regular post-operative instruction as they were advised precisely to have gentle irrigation after six hours of extraction with a cup of water and quarter spoon of salt once only. On the next three days they were advised to do a gentle irrigation 3-4 times a day. A follow-up appointment was given after one week for each patient. Patients were very compliance with the instruction.

The criteria for diagnosing the presence of dry socket included: 1- Presence of mild to severe pain. 2- Presence of halitosis. 3Presence of inflamed red gingiva area. 4- Presence of bear bone with empty socket 5- Presence of radiating pain to the ear and temporal area 6- Presence of ipsilateral lymphadenopathy. If any sign of dry socket appears before the review visit, patients were instructed to contact the clinic for urgent management.

Patients who developed alveolar osteitis were seen in the clinic and diagnosed according to the criteria mentioned above of dry socket. The onset of developing the symptoms and the severity of pain were reported. The severity of pain was graded as mild, moderate, severe, very severe and extremely severe. 
All procedures were done by one operator.

The research was registered at the College of Dentistry Research Centre, King Saud University with ethical approval number FR0175. Data were analyzed using SPSS software version 20 and for data comparison, a simple T- test was used were P value of $<0.05$ was considered significant.

\section{Results}

A total of 574 teeth extractions were done in the study for patients whom age ranged from 10 to 60 years. Out of the 574 cases 448 (78\%) were female and $126(22 \%)$ male. The total number of dry socket reported in this clinical study is 7 (1.2\%) cases (Table 1 and 2 ). Two cases were reported in the age group of 21-30, three cases in the age group 31-40, one case in the age group of 41-50 and one case in the age group above 60 years (Table 3). Of all dry socket cases reported in the current study, six were in females (1.04\%) and one in male $(0.2 \%)$ (Table 4$)$.

\begin{tabular}{|c|c|c|c|}
\hline \multirow{2}{*}{ Dry socket } & \multicolumn{3}{|c|}{ Irrigation } \\
\cline { 2 - 4 } & Yes & No & Total \\
\hline Yes & 2 & 5 & 7 \\
\hline No & 284 & 283 & 567 \\
\hline Total & 286 & 288 & 574 \\
\hline \multicolumn{2}{|c}{ Table 1: Dry socket and saline irrigation } \\
\hline
\end{tabular}

\begin{tabular}{|c|c|c|c|c|c|}
\hline Dry socket & Value & df & $\begin{array}{c}\text { Asymp. Sig } \\
(\mathbf{2}-\text { sided })\end{array}$ & $\begin{array}{c}\text { Exact Sig. } \\
\text { (2-sided) }\end{array}$ & $\begin{array}{c}\text { Exact Sig. } \\
(\mathbf{1} \text {-sided) }\end{array}$ \\
\hline Pearson Chi-Square & 1.281 & 1 & .258 & & \\
\hline Continuity Correction & 564 & 1 & .542 & & \\
\hline Likelihood Ratio & 1.323 & 1 & .250 & & .228 \\
\hline Fisher's Exact Test & & & & .450 & \\
\hline $\begin{array}{c}\text { Linear-by-Linear } \\
\text { Association }\end{array}$ & 1.278 & 1 & .258 & & \\
\hline N of Valid Cases & 574 & & & & \\
\hline
\end{tabular}

Table 2: Chi-Square Tests

\begin{tabular}{|c|c|c|c|c|c|c|c|}
\hline \multirow{2}{*}{ Dry socket } & \multicolumn{7}{|c|}{ Age } \\
\hline & $10-20$ & $21-30$ & $31-40$ & $41-50$ & $51-60$ & $>60$ & Total \\
\hline Yes & 0 & 2 & 3 & 1 & 0 & 1 & 7 \\
\hline No & 100 & 256 & 99 & 57 & 16 & 39 & 567 \\
\hline Total & 100 & 258 & 102 & 58 & 16 & 40 & 574 \\
\hline
\end{tabular}

Table 3: Dry socket and age

\begin{tabular}{|c|c|c|c|}
\hline \multirow{2}{*}{ Dry socket } & \multicolumn{3}{|c|}{ Gender } \\
\cline { 2 - 4 } & Male & Female & Total \\
\hline Yes & 1 & 6 & 7 \\
\hline No & 125 & 442 & 567 \\
\hline Total & 126 & 448 & 574 \\
\hline
\end{tabular}

Table 4: Dry socket and gender

All dry sockets were seen in healthy patients while only one case is seen in the diabetic patient. The seven cases of dry socket were reported in the mandibular teeth mainly the first and second molars (4 cases) while two in mandibular premolars and one in mandibular canine. None was reported in the maxilla. All cases of dry socket were reported by the second to third day post extraction.

Most of the dry socket cases developed in simple extractions cases with a low grade of difficulty (Table 5). Only two cases out of 286 developed dry socket where excessive irrigation with saline was used ( $\mathrm{P}$ value $>0.05)$.

\begin{tabular}{|c|c|c|c|c|c|}
\hline \multirow{2}{*}{ Dry socket } & \multicolumn{5}{|c|}{ Difficulty } \\
\cline { 2 - 6 } & Grade1 & Grade2 & Grade3 & Grade4 & Total \\
\hline Yes & 5 & 1 & 1 & 0 & 7 \\
\hline No & 510 & 44 & 7 & 6 & 567 \\
\hline Total & 515 & 45 & 8 & 6 & 574 \\
\hline
\end{tabular}

Table 5: Incidence of dry socket to due difficulty of extraction 
There was no dry socket developed in the quadrant where multiple extractions took place.

\section{Discussion}

The intention of this study was to explore the relation of through socket irrigation with saline after teeth extraction on the development of dry socket. In the literature, no documented evidence was found to correlate the effect excessive saline socket irrigation (saline irrigation established by the operator) and the development of dry socket. Although it was shown that excessive mouthwash will result in wash out of the clot from the extracted socket, there is no clear evidence to support its relation to the development of dry socket $[1,8,28]$. In the current study, out of 286 patients received excessive saline socket irrigation after teeth extractions, only two developed dry socket; while out of 288 patients received no immediate clinical saline irrigation, five developed dry socket. Therefore, the use of through socket irrigation with saline after teeth extraction has no positive relation to increase risk of developing of alveolar osteitis (Table 1).

The comparison using chi-square test showed no significant difference (Table 2).

The number of patients in this study is similar to other studies which investigated the development of dry socket $[19,26,27]$. The high numbers of female patients in the current study $(78 \%)$ was related to the fact that female patients prefer to be treated by a female dentist in our society.

The percentage of dry socket in the current study was reported to be $1.2 \%$, which is in consistent with other studies $[14,16,17]$. Field and coworkers 1985, MacGregor 1968, reported an incidence of dry socket of $0.5 \%-5 \%$. While it was $1 \%$ to $37.5 \%$ after extraction of mandibular third molars in some other studies [10,18]. It was $2.3 \%$ in the study of Partbasatbi and coworkers 2011 . Momeni and coworkers in 2011 reported only $0.6 \%$ of dry socket in their study; they explain their lower percentage by the difference in racial and geographical factors [28].

Some studies were able to correlate age and increase in the incidence of alveolar osteitis [5,28]. In the current study, most of the cases occurred in patients between 20-50 years of age (Table 3). Dry socket in the current study was reported as six cases in female patients $(1.04 \%)$ and only one case in male $(0.2 \%)$, (Table 4$)$. This is in consistent with many studies were more dry socket was seen in females compared to males [15,28]. The study of Abu Younis and Abu Hantash in 2011 reported no statistically significant association between the development of dry socket and patient's gender [19].

The medical condition of the patients has no influence on the development of dry socket in the current study as six cases were reported in healthy patients while one was reported in diabetic patients. This in consistent with Abu Younis and Abu Hantash 2011; while it contrasts the findings of other studies [7-9,19].

All dry socket cases in the current study were seen in mandibular teeth mainly molars and premolars. No cases were reported in maxilla. This is similar to the study of Momeni and coworkers 2011, where the incidence of dry socket in mandible was more than maxilla $(0.07$ versus 0.05$)$ but it was not statistically significant [28]. Khorasani and coworkers 2006, reported in their study an incidence of 2:5 times maxilla to the mandible [30]. Other studies reported a high incidence of dry socket in relation to the third molar area $[6,31]$.

In the current study, there was no relation between the difficulty of extraction and the increase in the incidence of dry socket. Five cases were reported in simple extraction while one developed after difficult extraction and one after surgical extraction (Table 5). This is inconsistent with many studies [5-7,16,28,32,33]. Brin 1973, explained the increase of dry socket in difficult extractions by the activation of activators secondary to bone inflammations which result in lysis of the clot [8]. In the study of Abo Younis \& Abu Hantash 2011, alveolar osteitis incidence following non-surgical extraction of teeth was 1.7\% while following surgical extraction was $12 \%$ [17]. In a study included 189 patients with 256 impacted third molars surgeries, the incidence of dry socket reported was $19.14 \%$ which is inconsistent with the current study [34].

In the current study, only 18 out of 574 cases were smokers but none of them reported having post extraction dry socket. Smoking showed no prevalence in the incidence of dry socket in the current study. This is in consistent with the study of Johnson and Blanton 1988 [35]. While it is inconsistent with many studies [17,21,22,28,33,36]. Sweet and Butler 1979, evaluate the incidence of dry socket and smoking among 4000 surgically removed mandibular third molars. They reported that patients who smoked half-pack of cigarettes a day had an increase in the incidence of dry socket $12 \%$ versus $2.6 \%$ when compared to nonsmokers while it increased to more than $20 \%$ among patients who smoked a pack per day and $40 \%$ among patients who smoked on the day of surgery [37].

\section{Conclusion}

Dry socket is a reported problem in the literature where many factors such as age, gender, site of extraction, the difficulty of extraction, medical condition and smoking have been investigated. In the current study, excessive socket irrigation with saline (completed by the operator) of the extracted socket has no positive relation to the increased incidence of dry socket.

\section{Acknowledgment}

The author would like to thank the College of Dentistry Research Center and Deanship of Scientific Research at King Saud University, Saudi Arabia for funding this research project. 


\section{References}

1. Howe GL (1970) The extraction of teeth. John Wright Bristol, ( $2^{\text {nd }}$ edn).

2. Osborn TP, Frederickson G, Small IA, Torgerson TS (1985) A prospective study of complications related to mandibular third molar surgery. J Oral Maxillofac Surg 43: 767-9.

3. Larsen PE (1992) Alveolar osteitis after surgical removal of impacted mandibular third molars: identification of the patient at risk. Oral Surg Oral Med Oral Pathol 73: 393-7.

4. Crawford JY (1896) Dry socket. Cosmos 38: 929-31.

5. Alexander RE (2000) Dental extraction wound management: a case against medicating postextraction sockets. J Oral Maxillofac Surg 58: 538-51.

6. Blum IR (2002) Contemporary views on dry socket (alveolar osteitis): a clinical appraisal of standardization, aetiopathogenesis and management: a critical review. Int J Oral Maxillofac Surg 31: 309-17.

7. Torres-Lagares D, Serrera-Figallo MA, Romero-Ruíz MM, Infante-Cossío P, García-Calderón M, et al. (2005) Update on dry socket: a review of the literature. Med Oral Patol Oral Cir Bucal 10: 81-5; 77-81.

8. Birn H (1973) Etiology and pathogenesis of fibrinolytic alveolitis ('dry socket'). Int J Oral Surg 2: 211-63.

9. Lilly GE, Osbon DB, Rael EM, Samuels HS, Jones JC (1974) Alveolar osteitis associated with mandibular third molar extractions. J Am Dent Assoc 88: 802-6. 10. Swanson AE (1990) Prevention of dry socket: an overview. Oral Surg Oral Med Oral Pathol 70: 131-6.

11. Fridrich KL, Olson RAJ (1990) Alveolar osteitis following surgical removal of mandibular third molars. Anesth Prog 37: 32-41.

12. Vezeau PJ (2000) Dental extraction wound management: medicating postextraction sockets. J Oral Maxillofac Surg 58: 531-7.

13. Hindle MO, Gibbs A (1977) The incidence of dry socket following the use of an occlusive dressing. J Dent 5: 288-93.

14. Rajendran R (2009) Shafer'S Textbook Of Oral Pathology, Elsevier India $\left(6^{\text {th }}\right.$ edn).

15. Thoma KH (1969) Oral Surgery ( $5^{\text {th }}$ edn) CV Mosby, Saint Louis, Mo, USA.

16. MacGregor AJ (1968) Aetiology of dry socket: a clinical investigation. Br J Oral Surg 6: 49-58.

17. Field EA, Speechley JA, Rotter E, Scott J (1985) Dry socket incidence compared after a 12 year interval. Br J Oral Maxillofac Surg 23: 419-27.

18. Heasman PA, Jacobs DJ (1984) A clinical investigation into the incidence of dry socket. Br J Oral Maxillofac Surg 22: 115-22.

19. Younis MH, Abu Hantash RO (2011) Dry Socket: Frequency, Clinical Picture, and Risk Factors in a Palestinian Dental Teaching Center. Open Dent J 5: 7-12.

20. Birn H (1970) Bacteria and fibrinolytic activity in "dry socket". Acta Odontol Scand 28: 773-83.

21. Birn H (1972) Fibrinolytic activity of alveolar bone in "dry socket". Acta Odontol Scand 30: 23-32.

22. Rud J (1970) Removal of impacted lower third molars with acute pericoronitis and necrotising gingivitis. Br J Oral Surg7: 153-60.

23. Kolokythas A, Olech E, Miloro M (2010) Alveolar Osteitis: A Comprehensive Review of Concepts and Controversies. Int J Dent 249073.

24. Nusair YM, Abu Younis MH (2007) Prevalence, clinical picture, and risk factors of dry socket in a Jordanian Dental Teaching Center. J Contemp Dent Pract 8: 53-63.

25. Motamedi MR (2015) To irrigate or not to irrigate: Immediate postextraction socket irrigation and alveolar osteitis. Dent Res J 12: 289-90.

26. Donald R, Hoaglin, Gary K. Lines (2013) Prevention of Localized Osteitis in Mandibular Third-Molar Sites Using Platelet-Rich Fibrin. Int J Dent 875380.

27. Partbasartbi K, Smitb A, Cbandu A (2011) Factors affecting incidence of dry socket: A prospective community-Based study. J Oral Maxillofac Surg 69:1880-4.

28. Momeni H, Shahnaseri S, Hamzeheil Z (2011) Evaluation of relative distribution and risk factors in patients with dry socket referring to Yazd dental clinics. Dent Res J 8: S84-7.

29. Blondeau F, Daniel NG (2007) Extraction of impacted mandibular third molars: postoperative complications and their risk factors. J Can Dent Assoc $73: 325$. 30. Khorasani M, Razavi F (2006) The prevalence and risk factors of dry socket in dental surgery clients following tooth extraction at Qazvin Faculty of Dentistry. JQUMS 10: 29-35.

31. Amaratunga NA, Senaratne CM (1988) A clinical study of dry socket in Sri Lanka. Br J Oral Maxillofac Surg. 26: 410-8.

32. Brekke JH, Bresner M (1986) Reitman MJ Effect of surgical trauma and polylactate cubes and granules on the incidence of alveolar osteitis in mandibular third molar extraction wounds. J Can Dent Assoc 52: 315-9.

33. Halabí D, Escobar J, Muñoz C, Uribe S (2012) Logistic regression analysis of risk factors for the development of alveolar osteitis. J Oral Maxillofac Surg 70: $1040-4$.

34. Eshghpour M, Nejat AH (2013) Dry socket following surgical removal of impacted third molar in an Iranian population: Incidence and risk factors. Nigerian J Clinical Practice 16: 496-500.

35. Johnson WS, Blanton EE (1988) An evaluation of 9-aminoacridine/gelfoam to reduce dry socket formation. Oral Surg Oral Med Oral Pathol 66: 167-70. 36. Sweet JB, Butler DP (1979) The relationship of smoking to localized osteitis. J Oral Surg 37: 732-5.

37. Sweet JB, Butler DP (1978) Predisposing and operative factors: effect on the incidence of localized osteitis in mandibular third-molar surgery. Oral Surg Oral Med Oral Pathol 46: 206-15. 